\title{
The Study on Teachers' Inspiring the Learning Motivation of College Students
}

\author{
Lieming Fang ${ }^{1, a}$, Weiran Zhang ${ }^{2, b, *}$ and Yuhua Wang ${ }^{3, c}$ \\ 1Shandong Youth University of Political Science, Jinan, China \\ Beijing Institute of Petrochemical Technology, Beijing, China \\ ${ }^{3}$ Party School of the Shandong Provincial Committee of C.P.C, Jinan, China \\ afanglieming@126.com, bzhangweiran@bipt.edu.cn, c2698600648@qq.com \\ *The corresponding author
}

Keywords: Learning Motivation; College Students; Strategies

\begin{abstract}
College students, as the main force for constructing an innovation-oriented country and a harmonious society, whose learning motivation is of vital importance. This paper makes a survey of the current situation of college students' learning motivation, elaborates the factors that influencing students' learning drive and puts forward the strategies for teachers to inspire the students' learning motivation.
\end{abstract}

\section{Introduction}

As the main force of the future society, college students are the important human resources for constructing an innovation-oriented country, a harmonious society and a powerful nation. They are the talent base for promoting the rapid development of economy, science \&technology and the driving force of progress. The lack of learning motivation of college students hinders on their own development and the building of a strong country. Therefore, the study on the students' learning motivation is of essential realistic importance.

\section{The Concept of Learning Motivation}

The so-called learning motivation refers to the psychological tendency of stimulating students to generate learning drive and advance towards a certain learning goal. The learning motivation is the fundamental drive of college students' learning and plays an important role in their learning process. College students' internal drive consists of three aspects:

(1) The interest. Learning interest refers to a positive cognitive tendency and emotional state of learning. If a student is interested in a subject, he/she will continue to devote himself/herself to it, which will generate motivation for learning and improve the learning effect.

(2) Cognitive drive. Cognitive drive includes professional prospect cognition, learning purpose cognition and learning attitude. Students' cognition of professional prospect and learning purpose will influence the motivation of learning, and a good learning attitude will directly influence the learning effect.

(3) Auxiliary drive. Auxiliary drive includes achievement, academic vision, self-worth, and confidence. The success of students in learning and participating in various activities is the motivation for students to learn. Academic pursuit and realization of self-worth are also the source of motivation for students' learning. Strong self-confidence is the key to students' success and the fundamental motivation for the pursuit of learning.

\section{The Current Situation of College Students' Learning Motivation}

Investigation about the present situation of college students' learning drive was conducted through questionnaires and the survey was made from three dimensions: interest, the cognitive drive 
(professional prospects, cognitive cognition, learning attitude, learning purpose), and the auxiliary drive(a sense of accomplishment, academic vision, self-worth and self-confidence).Please see the following table.

Table: The Present Situation of Learning Motivation of the College Students Surveyed

\begin{tabular}{|c|c|c|c|c|c|c|c|c|}
\hline \multirow{2}{*}{$\begin{array}{l}\text { Learning } \\
\text { Motivation }\end{array}$} & \multirow[t]{2}{*}{ Interest } & \multicolumn{3}{|c|}{ Cognitive Drive } & \multicolumn{4}{|c|}{ Auxiliary Drive } \\
\hline & & $\begin{array}{c}\text { Professional } \\
\text { Prospect }\end{array}$ & Goal & Attitude & $\begin{array}{c}\text { Sense of } \\
\text { Accomplishment }\end{array}$ & $\begin{array}{l}\text { Academic } \\
\text { Vision }\end{array}$ & Self-worth & Self-confidence \\
\hline $\begin{array}{c}\text { Strong Learning } \\
\text { Motivation } \\
\text { (number) }\end{array}$ & 305 & 325 & 647 & 309 & 561 & 457 & 558 & 305 \\
\hline $\begin{array}{c}\text { Strong Learning } \\
\text { Motivation } \\
\text { (percentage) }\end{array}$ & $38 \%$ & $40.5 \%$ & $81.7 \%$ & $40.1 \%$ & $71.2 \%$ & $57.9 \%$ & $71.5 \%$ & $39.1 \%$ \\
\hline $\begin{array}{c}\text { Poor Learning } \\
\text { Motivation } \\
\text { (number) }\end{array}$ & 275 & 190 & 86 & 129 & 119 & 167 & 109 & 149 \\
\hline $\begin{array}{l}\text { Poor Learning } \\
\text { Motivation } \\
\text { (percentage) }\end{array}$ & $36.5 \%$ & $24.9 \%$ & $10.1 \%$ & $16 \%$ & $15.2 \%$ & $20.7 \%$ & $18.9 \%$ & $30.8 v$ \\
\hline
\end{tabular}

Note: The others belong to the students with medium level learning motivation.

According to relevant statistics, students' general interest in learning is not very strong. They don't have a thorough understanding of their own majors, nor do they have clear awareness of their professional prospects. Many students don't know what to do with their majors or how to make life planning effectively with what they have learnt. Auxiliary drive, by contrast, is quite strong, which means that students hope to prove their worth by learning and get a sense of achievement. And there are a great number of students who realize the importance of professional learning, and hope to be able to achieve something in the academic aspect, which is indeed a very good trend. In a word, nowadays college students have a low level of internal drive for learning, and their cognitive drive is especially weak.

\section{Factors Influencing the Motivation of College Students' Learning}

Through conducting interview and consulting relevant literature, the authors summarized the factors that influence the learning motivation of college students:

(1) personal factor of college students such as students' confidence, personal cognition, sense of honor, expectation of the future, love affairs, game playing habits, interpersonal skills, number of clubs joined, and professional qualification exams taken.

(2) family factors such as college students' family financial situation, parents' work, family supervision. The influence of family environment on learning drive mainly comes from education. The positive education method enables students to establish correct belief and form good learning motivation.

(3) university factors such as campus environment, teaching methods, scholarships, university teaching system and learning environment. A good campus environment creates a good learning and development space for teachers and students.

(4) social factors. An important macro factor in social environment is cultural environment. The degree to which a country attaches importance to science and culture has a direct impact on students' learning drive. If grown in a nation valuing scientific knowledge, college students will work hard in the positive environment.

\section{Strategies for Teachers to Arouse College Students' Learning Motivation}

(1) Arouse the patriotic enthusiasm of college students and make it become their internal drive to study. 
Patriotism, the strong national pride and self-confidence, creates a powerful national vitality and cohesion and becomes the spiritual pillar of the nation and the people. While paying attention to students' academic performance, teachers also should pay more attention to the cultivation of patriotism and national identity. Teachers in the teaching process also need to help the student gain the sense of patriotism by showing the students the history of our civilization and the splendid traditional culture. By strengthening students' sense of national pride and sense of responsibility, inspiring their patriotic enthusiasm to fight for the future of our country, teachers can stimulate students' learning drive.

(2) Help college students make a good career plan to stimulate their learning drive.

Career helps for a person to integrate into society and realize his or her own

value. The degree of career development determines the satisfaction of his or her own needs and the realization of value. College students, as the main force of the future society, should be clear about their career goals, improve their ability and make a reasonable career planning. Since the right career planning is the premise to the career goal, teachers should fully understand the students' personality traits, ability, strong points and weaknesses, explain the career prospect, help students make scientific career planning and generate drive to learning.

(3) Understand the needs of students to stimulate their learning drive.

Teachers can strengthen students' learning motivation by understanding and meeting students' psychological needs. The formation and development of students' learning motivation is essentially the arousing and formation of psychological needs, and also the process of interconnection between psychological needs and the goal of satisfying them. Teachers need to know the psychological needs of students through observation, investigation and conversation. They should analyze the problems existing in the students' needs and whether the needs should be met, such as whether students play online game, whether they get the warmth of the family, the care of teachers and the friendship of classmates. By adopting effective reinforcement, which is what the students like and need, the school can meet the reasonable psychological needs of students, so as to strengthen their learning motivation and stimulate their learning drive.

(4) Inspire students' interest of learning to arouse their internal drive to learn.

Interest in learning has a close relationship with teaching methods. Many factors are beneficial to enhancing students' learning interest, for example, rich teaching contents, a variety of teaching methods, renewing teaching methods with the times, different kinds of interesting extracurricular activities and so on. The enhancement of students' interest in learning depends on the diversification of teaching methods. Nowadays the traditional teacher-centered method is no longer suitable for the development of education in schools. To enhance students' interest in learning, teachers should broaden students' thinking scope, adopt a variety of teaching methods, enlarge students' attention span and inspire the positive emotion of the students. The development of internet technology requires teachers to combine their teaching methods with the internet as much as possible. The use of slides, projectors and web has enriched the use of teaching methods and aroused students' interest. Outdoor activities and field practice can also bring more learning experience to students, which widen the scope of study and boost the interest of students.

(5) Give reward to students to inspire their learning motivation.

Since some students' learning motivation comes from the temptation of honor, money and so on, winning awards and bonuses is another driving motivation of college students' learning. In this respect, teachers can generate positive and negative incentives to college students through awards and punishment. Encourage students to participate in various competitions and social activities, cultivate students' communication competence, enhance their self-esteem, and improve their sense of achievement. Students are also encouraged to take part in various innovative activities and improve their academic standard.

(6) Teach students according to their aptitude and stimulate their learning drive.

The differences in students calls for teaching according to students' aptitude and teachers should fully develop students' personal strengths. In education, teachers should not only grasp the overall characteristics of students, but also take into account the individual characteristics of students. It is 
necessary to reform the traditional class teaching system, in which the best way to reform is to teach at different levels. The idea of level-based teaching originates from the idea of "teaching according to one's aptitude" proposed by Confucius, which is an important means of teaching according to students' actual learning level in the class teaching system. Level-to-level teaching can really achieve "students' development oriented teaching", and inspire learning initiative. Teacher should strive to help both the top students and the students of disadvantaged level to achieve their potential and make them succeed in learning.

(7) Create a good learning atmosphere to stimulate the learning drive of college students

A good learning atmosphere is not only conducive to the efficient running of teaching activities from week to week, but also can cultivate students' temperament, purify students' minds and encourage them to study hard. The main task of students is to study, and the quality of their academic performance is influenced not only by personal efforts, but also the cooperation and team work of students. Strengthening the awareness of cooperation among students and promoting cooperative behaviors are beneficial to improving students' learning level and forming a good academic atmosphere. In learning, students need to have a clear goal, take a right learning attitude and make a good learning atmosphere in class, so that students can help inspire the students to help each other, learn from others' strong points and make self improvement.

\section{Conclusion}

Strong youth make a country strong. Since college students are the future of the country, the teachers should effectively stimulate students' learning drive and inspire students to get more knowledge and enhance ability. In this way, student's growth as well as the social \& economic development will be promoted and the goal of building a powerful country be achieved.

\section{Acknowledgements}

The paper is funded by the following projects: 2013 Shandong Province-level University Great Course---"Labor Economics" (course No. 2013 BK386); A study on the "Student-centered" Model of College English Listening Teaching in Multi-modal Environment (ZD20160903); 2017 Overseas Study Program Funded by Shandong Provincial Government; Study on Teaching Design of Flipped College English Listening Class---From the Perspective of Cognitive Coupling Paradigm (SM201810017003).

\section{Reference}

[1] Fan Yiming. Comparative Analysis of Internal Learning Driving Force of Post-80s and Post-90s College Students[J]. Journal of Liaoning Teachers College. 2012(2): 56-57

[2] Hao Ying. Research on the Motivation and Guidance of College students' Internal Drive [J]. China Adult Education. 2015 ( 21) : 92-93

[3] Wang Jihong. Research on the Strategies to Stimulate the Internal Drive of College Students[J]. Journal of Hetao College. 2016(3): 39-42

[4] Bai $\mathrm{Ru}$. Educational Belief is the Driving Force of Educational Activities [J]. Journal of Kaifeng Education College. 2009(12): 56-57

[5] Xu Wei. Research on the Internal Drive of College Counselors' Career Development [J]. Research on Practice. 2017(4): 81-85 